to the quality or quantity of the food supplied on these private vessels, while on the vessels directly provisioned by the Admiralty there has been considerable grumbling, and at least one instance of alleged unfitness of the food.

The most interesting event of the week in the military medial preparations has been the completion of the hospital ship, the Princess of Wales, fitted up by the royal lady whose name she bears, at an expense of something like $\$ 50,000$. The ship itself was generously supplied by the Albion Steamship Company of Newcastle-on-Tyne, which also provided alul pays the wages of the entire ship's company. It is one of the most perfectly equipped vessels which has yet been sent out, being warmed by steam, cooled by electric fans and with an ice machine with a eapacity of half a ton of ice per day.

The largest single donation yet received for the care of the sick and wounded in the Transvaal was made this weok in the generous gift of the Duke of Portland. of $\$ 50,000$. to the English Red Cross Society.

The Irish Transvaal Society is adding its usual comic touch to the medical situation by elamorously demanding funds to enable it to send out an ambulance in the Boer service. The maiority of the journals rather regard this as an attempt to assist the Boer cause under the cloak of medical humanity, after their loud clamor for actual volunteers to aggressively assist the burghers has met with so little response.

The officers of the ambulance equipped and sent ont by Sir James Sivewright, although consisting largely of medical men of Duteh extraction, from Cape Colony and Natal, nobly announce their intention to assist the wounded of both sides equally, though probably the Boer wounded, needing more attention from the imperfect state of their ambulance service, will receive the greater share.

ROYAL COLLEGE OF SURGEONS.

The almost farcical annual meeting of the Members and Fellows of the Royal College of Surgeons was held this week, and as was expected, resolutions were passed severely criticising the council, for declining to ask for powers to extend the franchise to members, in the new charter. As only about forty of the niore than 10,000 members cared to be present we fear that the attitude of the council will not be much influenced by this vote. OPEN-AIK TREATMENT OF CONSUMPTION.

The splendid promise of the open-air treatment of consumption seems to be taking almost as firm a hold on the imagination of the English profession as on that of the public, as the crowded attendance at the formal discussion on this subject at the late meeting of the Medico-Chirurgical Society attested. Members were present from almost all over the kingdom, and so great was the interest of the discussion that it has announced that two more evenings will be devoted to the subject. PRESERVATIIES OF FOODS.

The daily press is directing a certain amount of half humor. ous, and not wholly undeserved, criticism against the attitude of some of the medical witnesses before the Commission on the Use of Preservatives in Foods, which is now in session. It aileges that it seems impossible to arouse much excitement in the medical mind of the dav, over any alleged intoxication, in which no microbe is to be discovered or even suspected, and complains of the cautiously worded and rather indefinite replies of the witnesses as to the probable effect of such preservatives as boric and benzoic acids, and even formalin, on the human system. They are exulting greatly over having finally got some positive evidence on this head, in the production of a body of a kitten, whose death had resulted from feeding on highly borated milk for a period of six weeks. This is aileged to be the only piece of positive evidence yet presented by our profession as to the actual injuriousness of these substances. It seems hard to bring home to the lay mind that the really important question about these mild food-preservatives is not as much their direct toxic effect as whether their use will cover up injurious fermentation and putrefaction changes in the foods themselves, especially in the case of milk, or allow uncleanly methods of preparing and handling to escape detection. DOUBLY RELATED TO THE PROFESSION.

Miss Chadwick, the sister superintendent of the Princess of Wales, hospital-ship, is doubly related to the profession, in that she is the niece of Mr. W. K. Treves, F. R. C. S., at Brighton, elder brother of the well-known surgeon.

\section{A Pathologic Department.}

To the Editor:- I was pleased to read in the Journal of December 2, a communication from Dr. Frank B. Wynn, on the above topic. I wish to heartily indorse the suggestions of Dr. Wynn, and urge that immediate steps be taken to consummate the plans for a national pathologic department. Based on the propositions laid down by the Doctor it will prove a success.

As a member of the Indiana State Medical Society, I can add my testimony to the value of the exhibit as shown at our annual meetings. It has grown to be a valuable collection, and is highly prized by our members as a real school of instruction in its special department. Our state society feels proud of this pathologic museum, especially as ours was the first state to move in the matter, and we give the largest amount of the praise to Dr. Wynn, who has been untiring in his efforts to make it a success. Respectfully

\section{G. W. H. KeMPER, M.D.}

\section{Yrxche, IxD., Dee. 4, 1899.}

To the Editor:-I have read with pleasure the letter of Dr. Frank B. Wynn of Indianapolis; Ind., in the JovrNal of December 2 , and take this opportunity of not only indorsing his idea of starting a section on pathology for the Association, but I also want to say that I am positive that it will meet with universal support from the physicians of this section, and I trust the subject will be considered by the officers of the Association, and favorable action taken at once. An exhibit of this character would undoubtedly draw large crowds to our annual meeting, and there could be no question that it would be one of the most instructive and interesting features that we could have to look forward to from year to year. The exhibit at Columbus, by the Indiana State Medical Society, last June, was to me in many respects the most interesting and instructive of any of the departments in connection with the meeting, and I am sure that it would prove equally so each year. The suggestion as 'made by Dr. Wynn should receive favorable consideration. inasmuch as he has demonstrated both in his letter and by practical experience, that the move can be made a success.

Respectfully,

Clarkmsburg, W. VA., Dec. 1, 1899.

M. P. GorF, M.D.

To the Editor:-In the December 2 issue of the Journal I note with pleasure a letter from Dr. Frank B. Wynn recommending the inauguration of pathologic exhibits at the meetings of the American Medical Assoctation, and $I$ earnestly hope that the Executive Committee of the Association will favorably consider the suggestions contained therein. I feel sure that all who had the pleasure of examining the pathologic exhibit of the Indiana State Medical Society at Columbus, Ohio, will indorse and recognize this unique innovation in society work as a feature of great interest and practical benefit, and it would seem unnatural if other states did not soon follow the excellent example. If the favorable editorial mention that this movement has received generally is at all significant, the establishing of a department of pathology in the National As. sociation must appeal to all those interested in the promotion of scientific medicine. If established along such a pian as suggested by Dr. Wynn, it would soon constitute a departure in Association work that would not only serve as a constant source of pride to the Association, but to its members--certainly be one of the most salient points of interest connected with the annual meetings of the Association.

$$
\text { Respectfully, Walter L. Bierring, M.D. }
$$

Professor of Pathology and Bacteriology, State University of Iowa.

Iow a City, Iowa, Dec. 8, 1898.

\section{Credit to Dr. Marlow.}

Dejver, Colo., Dec. 7, 1899.

To the Editor:-In "Sajous Annual and Analytical Cyclopædia of Practical Medicine," volume iv, occurs an error to which I would like to call attention. By mistake my name is appended to the article on "Diseases of the Lens," but the writer of this excellent paper, I am informed, was Dr. Frank W. Marlow, Syracuse, N. Y., and to him the credit for it is due.

EDWARD JACKson, M.D. 